\title{
Incidence of Post Operative Wound Infection Following the Use of Antibiotics in Clean Contaminated Head and Neck Surgery in a Tertiary Care Centre in Eastern Nepal
}

\author{
Chapagain $K,{ }^{1 *}$ Pokharel $R,{ }^{2}$ Acharya $R,{ }^{3}$ Shah $S,{ }^{4}$ Paranjape $B D^{1}$
}

\section{Affiliation:}

1. Department of Pharmacology, Nobel Medical College \& Teaching Hospital, Biratnagar.

2 Department of Otorhinolaryngology and Head and Neck Surgery, Koshi Zonal Hospital, Biratnagar.

3. Department of Otorhinolaryngology and Head and Neck Surgery, Nobel Medical College \& Teaching Hospital, Biratnagar.

4. Department of Otorhinolaryngology and Head and Neck Surgery, B. P. Koirala Institute of Health Sciences, Dharan-18, Sunsari, Nepal.

\section{ARTICLE INFO \\ Article History \\ Received : 25 Sept, 2016 \\ Accepted : 24 Oct, 2016 \\ Published : 20 Dec, 2016}

(c) Authors retain copyright and grant the journal right of first publication with the work simultaneously licensed under Creative Commons Attribution License CC - BY 4.0 that allows others to share the work with an acknowledgement of the work's authorship and initial publication in this journal.

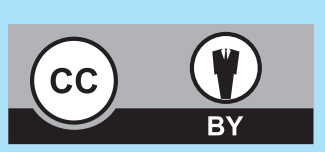

* Corresponding Author

Dr. Kumud Chapagai

Lecturer

Department of Pharmacology

Nobel Medical College \&Teaching Hospital, Biratnagar Email: kumudchapagain14@gmail.com

\section{Citation}

Chapagain K, Pokharel R, Acharya R, Shah S, Paranjape BD. Incidence of Post Operative Wound Infection Following the Use of Antibiotics in Clean Contaminated Head and Neck Surgery in a Tertiary Care Centre in Eastern Nepal. BJHS 2016; 1 (1) 1: 51-55.

\section{ABSTRACT}

\section{Introduction}

Post operative wound infection continues to be the major concern even after the appropriate antibiotic coverage.

\section{Objective}

To find out the incidence of post operative wound infection following the use of antibiotics in clean contaminated head and neck surgery in a tertiary care centre in Eastern Nepal.

\section{Methodology}

It is a prospective study conducted at Department of Otorhinolaryngology and Head and Neck Surgery, Nobel Medical College Teaching Hospital, Biratnagar from $14^{\text {th }}$ April 2013 to $12^{\text {th }}$ April 2015. Patient who underwent clean contaminated head and neck surgery were followed up on $1^{\text {st }}, 3^{\text {rd }}$ and $6^{\text {th }}$ post-operative day (POD) and wounds were inspected for any signs of wound infection.

\section{Results}

A total of 144 patients undergoing various clean contaminated head and neck surgeries were included in this study. Tonsillectomy was the commonest surgery performed (40.27\%). An overall wound infection rate was $11.80 \%$. Serous discharge from the surgical site observed on $3^{\text {rd }}$ post operative day was the most common presentation of wound infection (29.41\%). Parotidectomy was the surgery presenting with highest rate of wound infection (31.25\%).

\section{Conclusion}

This study concludes that even the best technique and appropriate antibiotic has not completely eliminated the problem of wound infection in clean contaminated head and neck surgery.

\section{KEY WORDS}

Antibiotics, ENT, wound infection 


\section{INTRODUCTION}

The Centre for Disease control and Prevention (CDC) for National Nosocomial Infections Surveillance (NNIS) system reports, wound infections are the third most frequently reported nosocomial infection. ${ }^{1}$ When surgical patient with nosocomial post operative wound infection died, $77 \%$ of the deaths were reported to be related to the infection, and the majority (93\%) was serious infections involving organs or spaces accessed during the operation. ${ }^{1}$ All patients undergoing head and neck surgery are also at high risk for post operative wound infection. Morbidity in early post operative period without administration of antibiotic ranges from $24 \%$ to $87 \%$ and with administration of antibiotics ranges from $14-40 \%$ in clean contaminated head and neck surgeries. ${ }^{2,3,4,5}$

Studies have shown that maximal effectiveness of the treatment is achieved if the antibiotics are given prior to contamination. The optimum duration of the prophylaxis has not been determined but is 2 to 7 days. ${ }^{6}$ Several antibiotics have shown to be effective in clean contaminated head and neck surgery including penicillin and its congeners (such as ampicillin and amoxicillin) as well as numerous cephalosporins, macrolides and clindamycin. ${ }^{7}$ The trend of using higher, newer and more expensive antibiotic is a financial burden to the patient. Issues such as efficacy, safety, antimicrobial spectrum, dosing schedules, compliance and cost should be considered in selecting the most optimal therapy. ${ }^{7}$

Amoxicillin and ampicillin+cloxacillin are the antibiotic of choice following clean contaminated head and neck surgery in the Department of Otorhinolaryngology and Head and Neck Surgery, Nobel Medical College Teaching Hospital. However, whether these antibiotics prevent the post operative wound infections in a developing country like Nepal is yet to be studied. Thus an attempt has been made to find out the incidence of wound infection following the use of antibiotics in clean contaminated head and neck surgeries in a tertiary care center in eastern Nepal.

\section{METHODOLOGY}

A prospective study carried out at the Department of Otorhinolaryngology and Head and Neck surgery, Nobel Medical College Teaching Hospital, Biratnagar, from $14^{\text {th }}$ April 2013 to $12^{\text {th }}$ April 2015.

Patients eligible to be included in this study were those scheduled to undergo clean contaminated head and neck surgery-tonsillectomy, parotoidectomy, hemithyroidectomy, sub-mandibular gland (SMG) excision, sistrunk's operation during the study period. Clean contaminated wounds were defined as sterile initially but the mucosal barrier was crossed or a potentially infected anatomical cavity was entered during the operation. Patients receiving systemic antibiotic within 72 hours prior to planned procedure, having clinical or laboratory evidence of a pre-existing infection, hypersensitive to penicillins, immunocompromised patients (diabetics, HIV positive, under immunosuppressive therapy) or pregnant females were excluded from the study. The protocol had been reviewed and approved by the Institutional Review Committee while informed consent was obtained from patients before the study.

According to the protocol of the department patients undergoing tonsillectomy, parotidectomy and SMG excision received amoxicillin $500 \mathrm{mg}$ eight hourly for seven days, starting the first dose night before surgery. Patients undergoing sistrunk's operation and hemithyroidectomy received ampicillin + cloxacillin $(250 \mathrm{mg}+250 \mathrm{mg})$ six hourly for seven days, starting the first dose night before surgery. These patients were then admitted in the wards night before surgery. All patients were followed up and inspected for any signs of wound infection on the first, third and sixth post operative day. Any surgical site presenting with erythema ( $<=1 \mathrm{~cm}$ ), increased tenderness / pain, swelling, purulent discharge, black dead tissue and wound gap were considered infected. Statistical analysis was done for descriptive statistics using frequency and percentage and tabular presentation was done accordingly.

\section{RESULTS}

During the period of two years, total of 144 patients fulfilling the inclusion criteria were enrolled in the study. Most of the patients were females (67\%) and $33 \%$ were male. Age of the patients ranged from 5 to 61 years and majority of the surgery (30\%) was performed at the age of 20-29 years. Tonsillectomy was the most common surgery performed (40.27\%). Table 1 shows the different surgeries performed and the respective antibiotics prescribed.

Serous discharge from the surgical site manifested as soakage of the bandage followed by pus discharge was the most common presentation of wound infection (Table 2)

In total, $11.80 \%$ of patients undergoing clean contaminated head and neck surgery presented with post operative wound infection. Parotidectomy was the surgery presenting with highest rate of wound infection (Table 3). 
Table 1 : Frequency distributions of different surgeries performed and antibiotics prescribed

\begin{tabular}{|lccc|}
\hline Surgery Performed & $n=144$ & Percentage (\%) & Prescribed Antibiotic \\
\hline Tonillectomy & 58 & $40.27 \%$ & Amoxycillin \\
\hline Hemithyroidectomy & 35 & $24.30 \%$ & Ampicillin + Cloxacillin \\
\hline Sistrunk's Operation & 25 & $17.36 \%$ & Ampicillin + Cloxacillin \\
\hline Parotidectomy & 16 & $11.11 \%$ & Amoxycillin \\
\hline SMG Excision & 10 & $6.95 \%$ & Amoxy \\
\hline Total & 144 & $\mathbf{1 0 0 \%}$ & \\
\hline
\end{tabular}

Table 2: Clinical features of patients on $1^{\text {st }}, 3^{\text {rd }}$ and $6^{\text {th }}$ POD

\begin{tabular}{|c|c|c|c|c|c|}
\hline Clinical Features & Surgery Performed & Antibiotic & $1^{\text {st }}$ POD & $3^{\text {rd }}$ POD & $6^{\text {th }}$ POD \\
\hline \multirow{5}{*}{$\begin{array}{c}\text { Serous Discharge } \\
\text { (Soakage of the } \\
\text { bandage) }\end{array}$} & Tonsillectomy & Amoxycillin & Absent & Present & Present \\
\hline & Parotidectomy & Amoxycillin & Present & Present & Present \\
\hline & Hemithyroidectomy & Ampi+clox & Absent & Present & Absent \\
\hline & Sistrunk's Operation & Ampi+clox & Present & Present & Absent \\
\hline & SMG Excision & Amoxycillin & Present & Present & Absent \\
\hline \multirow{3}{*}{$\begin{array}{l}\text { Discharge from } \\
\text { Wound + wound } \\
\text { Swelling }\end{array}$} & Tonsillectomy & Amoxycillin & Absent & Absent & Present \\
\hline & Tonsillectomy & Amoxycillin & Absent & Present & Present \\
\hline & Sistrunk's Operation & Ampi+clox & Present & $\begin{array}{l}\text { Only Soakage } \\
\text { Present }\end{array}$ & Absent \\
\hline \multirow{3}{*}{$\begin{array}{l}\text { Increasing } \\
\text { Wound } \\
\text { Pain }\end{array}$} & Tonsillectomy & Amoxycillin & Absent & Present & Absent \\
\hline & SMG Excision & Amoxycillin & Presnet & Present & Absent \\
\hline & Parotidectomy & Amoxycillin & Present & Present & Absent \\
\hline $\begin{array}{l}\text { Black dead Tissue } \\
\text { Around Wound }\end{array}$ & Parotidectomy & Amoxycillin & Absent & Present & Present \\
\hline \multirow{4}{*}{$\begin{array}{l}\text { Increasing redness } \\
\text { around wound }\end{array}$} & Parotidectomy & Amoxycillin & Absent & Present & Present \\
\hline & Tonsillectomy & Amoxycillin & Absent & Present & Absent \\
\hline & SMG excision & Amoxycillin & Absent & Present & Present \\
\hline & Sistrunk's operation & Ampi+clox & Present & Present & Present \\
\hline Wound gap & Parotidectomy & Amoxycillin & Absent & Present & Absent \\
\hline
\end{tabular}


Table 3 : Rates of wound infection in different surgeries

\begin{tabular}{|c|c|c|c|}
\hline \multirow[t]{2}{*}{ Surgery Performed } & \multirow[t]{2}{*}{ Antibiotic Prescribed } & \multicolumn{2}{|c|}{ Wound Infection } \\
\hline & & (n) & $(\%)$ \\
\hline Tonsillectomy & Amoxycillin & $5 / 58$ & 8.62 \\
\hline Hemithyroidectomy & Ampicillin+Cloxacillin & $1 / 35$ & 2.85 \\
\hline Sistrunk's Operation & Ampicillin + Cloxacillin & $3 / 25$ & 12 \\
\hline Parotidectomy & Amoxycillin & $5 / 16$ & 31.25 \\
\hline SMG Excision & Amoxycillin & $3 / 10$ & 30 \\
\hline \multicolumn{2}{|c|}{ Total } & $17 / 144$ & $(11.80 \%)$ \\
\hline
\end{tabular}

\section{DISCUSSION}

It has been long recognized that clean contaminated head and neck surgical procedure are having high risk of post operative wound infections. ${ }^{8}$ The incidence of these without administration of antibiotics ranges from $24 \%$ to $87 \%{ }^{1}$ The use of antibiotics these days have shown to significantly reduce these infections. Different studies reveal that with the use of antibiotics, infection rates range 14-40\%, ${ }^{9,10,11}$ However, even the best operative techniques and appropriate antibiotics have not completely eliminated this problem. To find out the rates of wound infection following the use of antibiotics in different head and neck surgeries is the rationale behind our study.

The most common presentation of patient undergoing clean contaminated head and neck surgery was serous discharge (29.41\%) from the surgical site manifested as soakage of the bandage. Serous discharge from the surgical site has been regarded as the most important criteria for diagnosing wound infection. ${ }^{12}$ Study conducted in Cleveland by Peel ALG et $\mathrm{al}^{13}$ and another study by Wilson AP et al. also reveals serous exudates as the most common manifestations of wound infection. ${ }^{13,14}$ Such serous discharge following clean contaminated head and neck surgery was commonly observed on $3^{\text {rd }}$ POD in this study. This contradicts Mark $\mathrm{K}$ Wax's findings where serous discharge is commonly observed on $5^{\text {th }}-7^{\text {th }}$ POD. However, Mark K Wax's also states that though serous discharge are commonly observed on $5^{\text {th }}-7^{\text {th }}$ POD, any discharge from closed surgical wound after 48 hours of closure is of concern. ${ }^{15}$ In our study tonsillectomy was the most common surgery performed $(40.28 \%)$. This supports the study conducted by Alississ A which reveals tonsillectomy as one of the most commonly performed clean contaminated head and neck surgery worldwide. ${ }^{16}$ Penicillin and its congeners (such as ampicillin and amoxicillin) is the recommended antibiotic for patients undergoing tonsillectomy and other head and neck surgeries.' However, there are controversies still going on how best prevent the post tonsillectomy morbidity. The first week after the surgery is extremely difficult for the patient. ${ }^{16}$ In our study wound infection rate following tonsillectomy was $8.62 \%$ and discharge from wound with wound pain was the most common presentation seen in $3^{\text {rd }}$ and $6^{\text {th }}$ POD. Tonsillectomy invades the oropharyngeal microflora. The lateral dissection injures the superior constrictor muscle. These could be the reason for wound infection in this study. Though tonsillectomy is expected to have higher rate of wound infection because of the oropharyngel microflora, the rate of wound infection is low in our study (8.62\%). The reason behind this finding could be the frequent antiseptic gargle offered to the patients along with antibiotic coverage.

In this study, seventeen patients receiving antibiotics developed wound infection. The highest overall infection rate was noted to be in parotidectomy (31.25\%), followed by submandibular gland excision (30\%). Longer duration of surgery and excess of tissue handling could be the cause of higher rate of wound infection in parotidectomy. One of the patient undergoing parotidectomy under coverage of amoxicillin presented with black dead tissue around wound on the $3^{\text {rd }}$ and $6^{\text {th }}$ POD. This may be due to the large area of flap elevation during the surgery which in turn may have led to the necrosis of the tip of the flap. Patients undergoing Sistrunk's operation received ampicillin+cloxacillin and presented with $12 \%$ of wound infection. In surgeries involving the skin and soft tissue, ampicillin + cloxacillin would be the better choice as far as the sensitivity and normal flora of the skin is concerned. In Sistrunks operation, usually the core tissue from the base of the tongue is not well defined and attempt to excise the tissue can break the oropharyngeal 
mucosa leading to the contamination of the surgical field. This could be the cause of the wound infection in our study. Similarly, in submandibular gland excision, injury to the mucosa on floor of mouth, injury to submandibular duct and leakage of the content of the duct to the surgical field could be an issue leading to higher rate of wound infection. Oozing from the salivary tissue leading to serous discharge which in turn would have led to inflammatory changes in the surgical site could be reason behind the higher rate of wound infection (30\%) following submandibular gland excision in this study.

Thus, amongst all the patients undergoing clean contaminated head and neck surgery under coverage of amoxicillin and ampicillin + cloxacillin, post operative wound infection was found to be present in $11.80 \%$. However, this contradicts the findings of Skitarelic N, where the wound infection rate was $24 \%$ in patients undergoing clean contaminated head and neck surgery. ${ }^{8}$

\section{CONCLUSION}

This study concludes that even the best technique and appropriate antibiotic has not completely eliminated the problem of wound infection in clean contaminated head and neck surgery. The appropriate use of antibiotics in patient care is very important but it cannot be a substitute for good surgical technique.

One of the limitation of this study is only two antibiotics have been used for surgical prophylaxis. It would have been more comparable if different antibiotics have been used.

\section{ACKNOWLEDGEMENT}

The authors are grateful and acknowledge all the patients participating in this study.

\section{REFERENCES}

1. Weber and Callender. Antibiotic prophylaxis in clean contaminated head and neck oncological surgery Ann Otol Rhino laryngolo 1992;101:16-202

2. Edwards PS, Lipp A, Holmes A. Preoperative skin antiseptics for preventing surgical wound infections after clean surgery. Cochrane Database Syst Rev. 2004;(3):CD003949

3. Cole RR, Robbins KT, Cohen JI, Wolf PF: A predictive model for wound sepsis in oncologic surgery of the head and neck. Otolaryngol Head Neck Surg 96;1986:165-171

4. Girod DA, McCulloch TM, Tsue TT, Weymuller EA. Risk factors for complications in clean-contaminated head and neck surgical procedures. Head Neck17;1995: 7-13

5. Rodrigo JP, Alvarez JC, Gomez JR, Suarez C, Fernandez JA, Martinez JA. Comparison of three prophylactic antibiotic regimens in cleancontaminated head and neck surgery. Head Neck 19;1997: 188-193

6. Johnson JT, Schuller DE, Silver F, et al. Antibiotic prophylaxis in highrisk head and neck surgery: one-day vs. five-day therapy. Otolaryngol Head Neck Surg. Dec 1986;95(5):554-7

7. Homer SV. Surgical site and vascular infections: treatment and prophylaxis. Int J Infect Dis 11; 2007:17-22

8. Skitarelic N, Morovic M, Manestar D. Antibiotic prophylaxis in clean contaminated head and neck oncological surgery: J Cranio Maxillofacial Surg 2007:35,15-20

9. Cole RR, Robbins KT, Cohen JI, Wolf PF: A predictive model for wound sepsis in oncologic surgery of the head and neck. Otolaryngol Head Neck Surg 96;1986:165-171

10. Girod DA, McCulloch TM, Tsue TT, Weymuller EA. Risk factors for complications in clean-contaminated head and neck surgical procedures. Head Neck17;1995: 7-13

11. Johnson JT, Schuller DE, Silver F, et al. Antibiotic prophylaxis in highrisk head and neck surgery: one-day vs. five-day therapy. Otolaryngol Head Neck Surg. Dec 1986;95(5):554-7

12. Cutting KF, White RJ, Mahoney P, Harding KG. Clinical identification of wound infection: a Delphi approach. In EWMA Position Document. Identifying criteria for wound infection. London: MEP Ltd,2005

13. Peel ALG, Taylor EW. Surgical Infection Group. Proposed definitions for the audit of postoperative infection, a discussion paper. Ann R Coll Surg Engl 1991; 73:385-88.

14. Wilson AP, Gibbons C, Reeves BC, et al. Surgical wound infection as a performance indicator: agreement of common definitions of wound infection in 4773 patients. BMJ 2004; 329:720-23

15. Wax MK. Primary care otolaryngology. American Academy of Otolaryngology-Head and Neck Surgery. 2011,3:5-9

16. Alississ A, Rashdan H, Maita A, Saraireh M. Antibiotics for PostTonsillectomy Morbidity: Comparative Analysis of a Single Institutional Experience. J Clin Med Res. 2016 May;8 (5):385-388 